\title{
Construction and Empirical Study of Social Business Model on Niche Products
}

\author{
Q.W. Ye \\ The department of business, Yunnan University of Finance \\ and Economics \\ Kunming, China
}

$$
\text { Q. Zhang }
$$

The department of Finance and Economics

Yunnan University of Finance and Economics

Kunming, China

\author{
S. Zhong \\ The department of business \\ Yunnan University of Finance and Economics \\ Kunming, China \\ G.X. Song \\ The department of business \\ Yunnan University of Finance and Economics \\ Kunming, China
}

\begin{abstract}
With the rapid development of social networks like Facebook and WeChat and so on, the social characteristics of the emerging e-commerce has become increasingly prominent and the varied demand for products rises in the same way, and the commercial value of niche products has also been surging with a blowout type, which suggests that the business model of niche products owns unique research value. Thus, the paper starts with the characteristics of niche products and their level of market demands, combines with the information diffusion characteristics of social networks, proposes the Business to (the Social Network Service)SNS to Customers (B2S2C) model and takes walnut oil products as example to empirically demonstrate this social commerce model. The empirical results show that the B2S2C social business model can reduce the high cost of middlemen, increase market share of niche products and ultimately achieve a significant improvement for its business efficiency, which suggests strong guiding significance and practical value for the product positioning and business model innovation for social network environment.
\end{abstract}

Keywords-social commerce; niche products; the long tail; social networks; the B2S2C Model

\section{INTRODUCTION}

Thanks to the progress of technology and the improvement of material living conditions, people's requirements have rapidly increased both in products' capabilities and characteristics, the "brick and mortar" model that traditionally focus on products' quality and service has been far more dissatisfied the current growing needs for products' diversification. An additional $30-40 \%$ of the sales is obtained by Amazon's sales model which can never be reached under the "bricks and mortar" model [1], and the authorization of allowing consumers to search niche products has created more than one billion dollars of consumer surplus each year [2]. The tastes of consumers are multi-dimensional and infinite, and they rarely exhibit strong consistency within what they need [3][4] Therefore, it is reasonable and necessary to study how to propose suitable business model for niche products form the vision of the diverse needs of products. In addition, more intensive social networks can spread information more effectively [5] What's more, an American consumer psychology test shows that the impact of shopping intention of a friend recommendation is 12 times more than the impact of the hardware online advertising. At last, the paper combines the advantages of social networking in information diffusion and the features of niche products, construct the social business model based on niche products, which try to innovate business model theoretically and take the actual enterprise as example to study the model empirically and enhance its practical value further.

\section{Niche Products AND Social Business Model}

\section{A. Niche Product}

Niche products is relatively defined in terms of the public products and popular products and involves to products with lower market shares and limited sales, which becomes a part of product division based on products' popularity, and there are blockbuster products and hit products between popular products and niche products[5]. However, Larson [6] defines the lowly dispersed products as general products and the high dispersion product as niche products (Nathan, 2011). Niche products' research mainly involves to the long tail theory[7], which can be expressed as that the creation of $80 \%$ of its sales is derived from the first $20 \%$ products in the Pareto's Principle or the "80/20" Rule[1]. Long Tail theory refers to that in the current personalized era, some products' sales curves present the change mode of "power curve", of which the "head" portion present popular products and the unpopular products constitute the "long tail" followed behind the "head". The long tail has made a good complement to the Pareto's "80/20" rule [8].However, Larson [6] believe that a balanced product design exists a feedback loop, within which the marginal degree of matching with consumers will be advanced by the appearance of niche products when the reservation utility is high, and vice versa. At the same time, vendors will synthetically weigh different product costs as well as strategies (avoiding price wars, etc.) and select different product line relatively [6]. Harwin [9]deems that the model design for niche products depends on further subdividing for certain products . 


\section{B. The Social Commerce Model}

Business model is a basic business management methods, including customer value proposition, profit formula, value chain location as well as key resources and processes. Curty[10]simply describes social commerce as business activities via social media; Oestreicher-Singer[11] believes that social commerce model is a by-product accompanied by recent increasingly frequent e-commerce and interactive activities, and linking the products and consumer electronic network visualization have contributed its appearance. Stephen and Toubia [12] subdivides social commerce into social shopping (with the user's direct participation) and social business (only sales participation) depending on the type of participants. Originally, Burt [13]summarizes social networks via structural-hole theory and highlights the importance of the bridge nodes (opinion leaders in information and behaviour diffusion within the Small-world network) (Burt, 2009). More widely Centola [5] deems that cluster network (three signal propagation probability maximum impact: 40\%) is more conducive to information diffusion with respect to the random network (Damon, 2010). Therefore, the study of how to weigh between the Riches and Niches turns out to divide products further on the basis of product characteristics in order to discover the characteristics with high quality within niche market demand.

\section{B2S2C SOCIAL COMMERCE MODEL BUILDING}

The business model of socialization of niche products research is laid emphasis on the topological structure of social network as well as characteristics of its products [5][13][14] which can be developed from 3 perspectives, such as strengthening permeating of network, applying $\mathrm{O} 2 \mathrm{O}$ model and bundling-sale.

\section{A. Grasp the Core Users, and Strengthen Network \\ Penetration Ability of Characteristic Product}

Due to the surge of User-Generated Content (UGC), it is effective to mining core users by technical means, improve product penetration rate within the concept of potential customer groups through information propagation characteristics of social networks, form a positive and effective product perception, and enhance the accept intention for their promotions. The enterprise should strengthen the integration among personalized features of the product and the concept of health and culture, enhance the conceptual product positioning, and finally create conditions for overall good products perception by maintaining and strengthening relationships with prospective customers through products' effective quality management and services, and increase customers' stickiness.

\section{B. Take Advantage of the O2o Mode and Integrate Promotion Product Concept Online and Supply of Popularization Product Offline}

It is inevitable for the innovation and development of business model to achieve the dual optimization both of customers' product experience and saving costs by integrating online and offline products [14]. Most successful business model cannot separate from the support of online and offline integrated marketing (Su, 2012), such as the Apple's offline- experience and online-distribution model, which adopt the online order model that base of customers' good experience and in order to save inventory cost. Unlike Apple's model, the standpoint of niche products is to spread product opinion through the online social networks with the help of offline channel distributor. In contrast, it is undoubtable that this promotion model is popular with the niche products that can be popular in terms of not only the cost but customers' support.

\section{Bundling-sale associated with (alternative or complementary) and promoted of the new niche}

As part of corporate strategy, it is necessary for business success to grasp the changes of market timely and flexibly and make the right decisions[15] [16] [17]. Furthermore, it is reasonable for niche products through the bundling strategy.

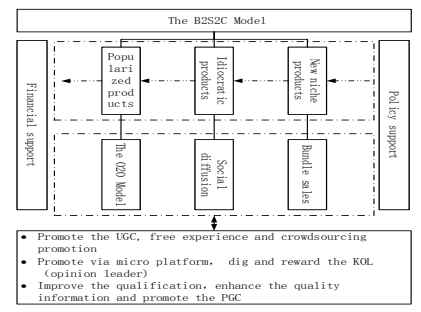

FIGURE I. B2S2C SOCIAL COMMERCE MODEL DIAGRAM.

Figure I .concludes the analysis and supplement above, and bring further insights from the product positioning inside and its promotion paths and the support of external policy environment. On the one hand, the social commerce mode (B2S2C) mode for niche products needs the support of external environment, mainly financial support and government policy support, which is also necessary for the implementation of the business model and its landing. On the other hand, it is mainly the guidance of internal conditions: Firstly of all, place product segment for niche products, subdivide products according to the production stage and its existing demand secondly. Last but not at least, it should be noted that there may be crossed effects between the product promotion paths and its corresponding products segment.

\section{EMPIRICAL RESEARCH OF B2S2C MODE}

$\mathrm{XS}$ is a typical private enterprise in Yunnan Province which has a large-scale wild walnuts and walnut oil products, it's walnut oil products has low product sales and limited market share due to the obstacle of product cost information communication and the impact of consumer awareness' lack both in domestic and abroad. Thus, XS company's main products are included in the scope of niche products. Meanwhile, due to the stimulation of social networking in recent years, the company has also been socialized practice based on niche product business model. 


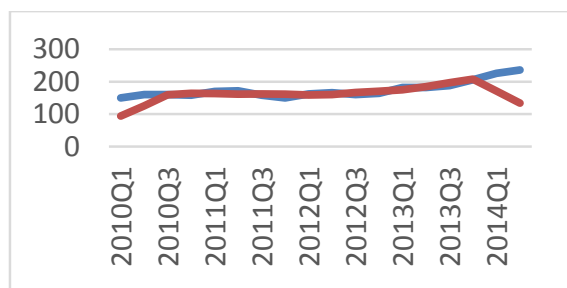

FIGURE II. AFTER A FIFTH-ORDER MOVING AVERAGE PROCESS XS COMPANY ACCOUNTS AND COST DATA.

Figure II . shows the relationship between XS company's total revenue and total cost after the cyclical adjustment carried out: Before adjusting the business model, the traditional middlemen to more than two percent of the total share of the total cost of business, despite XS carried out more try off line, but it is limited by the informational disadvantages of the niche product and the high cost features, the company's revenue and cost begin stalled with saturated market of effective demand, and overall profit growth slow; However, after the adjustment in the company's business model, on the one hand, companies bear fruit in focused on building online product concept of health promotion model, and gradually reduce its reliance on the line brokers and product costs; on the other hand, there have done the effective promotion of their products through social way of the spread of information. Further, improving enterprise revenue while reduce a huge amount of costs waste caused by middlemen, make the company's revenues and costs began to shunt.

\section{A. Products Division}

XS company is originate from operating the high-end organic walnut oil, due to limited by the high cost of raw materials from product inherent and the input of $\mathrm{R} \& \mathrm{D}$, the price of product increasing, and together with the fault acknowledge from potential customers for the inherent error in walnut oil products (oil products) leads product information difficult to spread between producers and consumers. Furthermore, there is a lack of promotion of the power brokers and affected by the cost of the monopoly channel of dealers accounted for three percent of the total costs, which have led to poor sales market walnut oil products. XS company maintains its competitive organic of walnut oil and at the same time segment the products correspondingly, take the low-cost ordinary walnut oil which can be market-based into the category of product management. Thus, this result in effective organization and distinction in the product categories.

\section{B. Product Promotion Path}

Furthermore, XS Company put the product promotion mainly into traditional business markets before the adjustments of business model, however, because of the customers' perception errors of the products' characteristic and the negative promotion of dealers, walnut oil product is difficult to open the market in physical sales. While the corresponding adjustments of business model compensate for users' perception of bias resulted by information curing stagnant in niche products, and distinguish promotional strategy according to the dimensions of the different product segments [16] [17], namely start the ordinary walnut oil online promotion by the use of $\mathrm{O} 2 \mathrm{O}$ mode and supported by offline users' experience and promotion, using strong penetration of the role of social networks, increase organic walnut oil products leading a healthy life concept of publicity, mining core users and reward micro-blogging and micro-channel marketing, promoting UGC; at the same time, increase the walnut oil R\&D investment, improve product quality and its core competitiveness.

\section{CONCLUSIONS}

The success of the company's business strategies could not escape the grasp of effective demand for the changes in the market, the article has carried on the empirical analysis by building a business model named B2S2C and use XS company for example, the conclusions are following :Firstly, the social business model of niche products should be excavated key users, taking advantages of the spread of social network information to make up the obstacle of the niche products' information dissemination. Secondly, we should grasp the demand characteristics of market segments effectively, detail product segments, delimit the leading products and the following products flexibly, designated product ecosystem reasonably, and according to the different segments of the product set the appropriate products promotion strategies, which correspond to the $\mathrm{O} 2 \mathrm{O}$ mode of popular products available, the promotion way of characteristic product of social diffusion as well as the bundling mode of new niche products. Finally, companies in the implementation of social commerce model should also pay attention to the external environment and support efforts to increase the integration of resources, absorb and utilize external value factor, broadening the use of information and channels to raise capital, and make the business strategy tailored for the effective operation of company.

The article has carried on the comprehensive analysis for business model of niche products, and do an effective product segmentation and promote the mechanism design for niche products. However, as an effective extension of the business model innovation, related researches must be able to lay a foundation for the optimization and upgrading business model if it can focus on strategy formulation process and set up index evaluation system. And this leading a direction for the further research of the thesis and ascend.

\section{ACKNOWLEDGEMENTS}

This research was supported by the National Natural Science Foundation of China under Grant 71162005, 71362015 \& 71362016

\section{REFERENCES}

[1] E. Brynjolfsson, Y.J. Hu and M.D. Smith. From Niches to Riches: The Anatomy of the Long Tail. Sloan Management Review, 47(4),pp: 67-71, 2006.

[2] E. Brynjolfsson. Y. J. Hu and M. D. Smith. Consumer surplus in the digital economy: estimating the value of increased product variety at online booksellers. Management Science, 49 (11), pp: 1580-1596, 2003.

[3] A. Elberse. Should You Invest in the Long Tail? Harvard Business Review: Reader's Guide, 2008.

[4] A. Davies, M. Hobday. The business of projects: Managing innovation in complex products and systems. Cambridge University Press, 2005.

[5] D. Centola. The Spread of Behaviour in an Online Social Network Experiment. Science, 329, pp: 1194-1197 2010. 
[6] N. Larson. Niche products, generic products, and consumer search. Economic Theory, 52, pp: 793-832, 2013.

[7] C. Anderson. The long tail: Why the future of business is selling less of more. Hachette Digital, Inc., 2006.

[8] P.P. Li. The analysis of content and application of the Long Tail. Southeastern Spread, 2, 2008.

[9] W.S. Harwin. Niche product design, a new model for assistive technology. IOS press, pp: 449-452, 1998.

[10] R.G. Curty, P. Zhang. Social commerce: Looking back and forward. Proceedings of the American Society for Information Science and Technology, 48 (1), pp: 1-10, 2011.

[11] G. Oestreicher-Singer, A. Sundararajan. Recommendation networks and the long tail of electronic commerce. MIS Quarterly, 36 (1), pp: 65-83, 2012.

[12] A.T. Stephen and O. Toubia. Deriving value from social commerce networks. Journal of marketing research, 47 (2), pp: 215-228, 2010.

[13] R.S. Burt. Structural holes: The social structure of competition. Harvard University Press, 2009.

[14] T. Su. The analysis of new $\mathrm{O} 2 \mathrm{O}$ model of e-commerce business. National Business Information, 1, 2012.

[15] M.X. Zheng. Handle the demand of customers in the changing world. Traffic world: transport vehicles, 11, 2013.

[16] Sun, Y. Zhao and Q.H. Zhu. Understanding the niche strategies adopted by social commerce websites. Information Management, Innovation Management and Industrial Engineering (ICIII), 2012 International Conference on IEEE, 1, pp: 418-421, 2012.

[17] Y. Wei. The analysis of "product ecosystem" of travel industry based on APP Store business model. China trade, 14, pp: 36-37, 2011. 